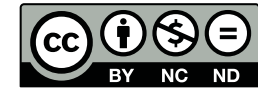

Estudos Teológicos foi licenciado com uma Licença Creative Commons Atribuição - NãoComercial - SemDerivados 3.0 Não Adaptada

http://dx.doi.org/10.22351/et.v58i1.3171

\title{
PIBID de Ensino Religioso: uma proposta de educaÇão para RELAÇÕES DE EQUIDADE EM CONTEXTOS DE DIVERSIDADE RELIGIOSA ${ }^{1}$

\author{
PIBID of Religious Education: a proposal for education for equity \\ relations in contexts of religious diversity
}

\section{Elisa Rodrigues ${ }^{2}$ \\ Tania Alice de Oliveira ${ }^{3}$}

\begin{abstract}
Resumo: $\mathrm{O}$ artigo apresenta o Programa Institucional de Bolsa de Iniciação à Docência (PIBID) como política pública de formação de docentes, que na Universidade Federal de Juiz de Fora (UFJF) promoveu o subprojeto Ensino Religioso, proposto pelo Departamento de Ciência da Religião responsável pela licenciatura em Ensino Religioso. Esse subprojeto (2014-2018) aborda o tema religião na escola pública e contribui para a formação de futuros docentes. Além disso, colabora para uma discussão sobre as diferentes tradições religiosas brasileiras em perspectiva compreensiva. A partir da concepção de que as tradições religiosas enquanto área cognoscível também contribuem para explicar a realidade, o PIBID intenciona oferecer novas fontes de conhecimento fundamentadas pelo respeito à laicidade da escola pública.
\end{abstract}

Palavras-chave: PIBID. Ensino Religioso. Escola pública.

Abstract: The article presents the Institutional Program of Scholarship for Initiation to Teaching (PIBID) like public politic for preparing teachers, that in the Federal University of Juiz de Fora (UFJF) promoted the sub-project for Religious teaching, propose by Science Religion Department responsible for the Religious teaching degree. This sub-project (2014-2018) addresses the religion subject in the public school and contributes with the formation of teachers to the future. Besides, it collaborates to discuss about the different Brazilians religious traditions in comprehensive perspective. From the conception that religious traditions as a knowledgeable field also contribute to explain reality, PIBID intends to offer new sources of knowledge based on respect for the secularity of the public school.

Keywords: PIBID. Religious teaching. Public school.

1 O artigo foi recebido em 27 de novembro de 2017 e aprovado em 10 de maio de 2018 com base nas avaliações dos pareceristas ad hoc.

2 Professora, doutora do Departamento de Ciência da Religião da Universidade Federal de Juiz de Fora/ MG e coordenadora do Grupo de Pesquisa REDUGE - Religião, Educação e Gênero.

3 Mestre e doutoranda em Ciência da Religião pela Universidade Federal de Juiz de Fora/MG, professora da rede municipal de ensino de Juiz de Fora/MG e pesquisadora do Grupo de Pesquisa REDUGE -Religião, Educação e Gênero. 


\section{Introdução}

Tentar compreender um fenômeno ambíguo e polêmico como é o caso da religião, que cada vez mais vem se apresentando como um discurso que reivindica participação nos mais variados espaços, revela-se tarefa árdua e ousada quando se requer observá-la no interior da escola pública básica. Especialmente no período político e social que o país e o mundo contemporâneo atravessam, o qual, entre muitos desafios, nos impõe conviver com a ameaça de exclusão de programas e investimentos essenciais para a educação.

Neste artigo, a tentativa de mostrar a abrangência do fenômeno religioso e, em especial, como ele dinamiza as relações sociais escolares influindo sobre elas pretende: 1) dar visibilidade a esse tema que interfere nas práticas docentes e no aprendizado dos/as educandos/as, e 2) inspirar novos trabalhos a encarar tal tarefa, a fim de estabelecer parcerias dentro e fora da escola que contribuam para a orientação quanto ao "como" lidar com a religião dentro dos espaços escolares.

Nesse sentido valem dois esclarecimentos importantes, quais sejam: 1) tratar a religião enquanto conteúdo legítimo sobre o qual se pode aprender com a finalidade de conhecê-lo difere do 2) tratamento da religião na condição de experiência, vivida e alimentada por pessoas, de diferentes modos. Tendo em vista que o PIBID - Programa Institucional de Bolsa de Iniciação à Docência - corresponde a um programa que visa à formação de licenciandos para a atuação enquanto docentes em escolas do sistema público de educação, a religião é tomada aqui como conhecimento humano sobre o qual se pode pensar, refletir e aprender; considerando-o assim uma importante parte da história da humanidade.

É pressuposto deste artigo que pensar questões atinentes à educação, como o tratamento do fenômeno religioso na escola, a fim de contemplar o desenvolvimento pleno de nossos educandos e educandas, tendo como horizonte uma sociedade justa e igualitária, a partir de um projeto como o PIBID de Ensino Religioso (ER), atravessa ainda outras questões não menos importantes, tais como: quando vamos discutir a invisibilização dos povos de santo cujas identidades são ameaçadas na escola? Quando vamos refletir sobre os processos migratórios que ocorrem em função da "guerra santa" na Síria? Quando e onde vamos falar sobre os usos que as pessoas fazem de turbantes e outros objetos religiosos em espaços privados e públicos? Onde seria o lugar para discutir expressões cada vez mais frequentes no cotidiano como "apropriação cultural", "sincretismo religioso" e "campo religioso"?

Visando responder essas indagações emerge o projeto PIBID de Ensino Religioso do Departamento de Ciência da Religião da Universidade Federal de Juiz de Fora, no interior do qual se pretende que o licenciando e professor que pleiteie enveredar por esse caminho disponha de uma formação que aborde a) desde os meandros que transformam uma política pública transitória em permanente, b) até as contribuições da Ciência da Religião como área de referência para o ER (que oferece uma nova identidade para esse componente curricular, com método, conteúdo e objeto) e, por fim, c) fomente a percepção sobre o campo religioso local com suas tensões, negociações e reconfigurações. 
Ressalta-se que essa nova identidade do ER não se sobrepõe de forma diacrônica aos demais modelos praticados no Brasil. Essa nova proposta ${ }^{4}$, além de estar em consonância com o artigo $33^{5}$ da Lei de Diretrizes e Bases para a Educação Nacional (LDBEN), busca atender às atuais demandas de uma sociedade multicultural e religiosa que nos impele a assumir posturas reflexivas e críticas como educadores.

Tal investida, neste caso, pressupõe não haver mais espaço para o proselitismo religioso na mesma proporção em que está sensível à urgência de diálogo com a religião enquanto uma das esferas sociais que nos ajuda a entender a conjuntura mundial vigente. Isso pode parecer paradoxal, mas trata-se de um novo olhar que nega o ensino proselitista na escola pública, uma vez que enxerga a religião como parceira na busca por outras fontes de conhecimento. Isso significa dar voz às demais instâncias do saber, inclusive a religiosa, oportunizando ao corpo discente uma compreensão mais integralizada e dialógica da realidade que o cerca.

Nesse quadro, muitas questões estão suscitadas, no entanto, serão tratadas aqui aquelas que identificam o ponto de partida de nossa análise. Com isso, a abordagem do binômio: tolerância/intolerância será tangenciada, porque nos ajuda a mostrar o quão tênues podem ser as fronteiras que separam os dois conceitos e como ainda confundimos os axiomas. Concepções de educação e laicidade do Estado também serão tocadas, uma vez que este último conceito se torna o grande entrave para a maioria dos educadores que alegam não ter recebido formação nas licenciaturas e, assim, reproduzem na escola o silenciamento das graduações que conferem ao tema religião status de foro íntimo, marginalizando-o assim.

\section{Desenvolvimento}

\section{Acertando a questão, problematizando conceitos}

Em busca de afirmação e legitimação no campo, as religiões desqualificam-se umas às outras resultando em desigualdades que se refletem no espaço escolar reproduzindo empiricamente o que ocorre na sociedade. Nesse contexto, a escola, sob a confortável alegação de instituição laica, muitas vezes isenta-se de qualquer responsabilidade sobre as formas como essas relações de desigualdade se delineiam

4 Através da Lei 9.475/97, o artigo 33 da LDBEN, de 20 de dezembro de 1996, que estabelece as diretrizes e bases da educação nacional, ganha nova redação. Vejamos: "Art. 33. O ensino religioso, de matrícula facultativa, é parte integrante da formação básica do cidadão e constitui disciplina dos horários normais das escolas públicas de ensino fundamental, assegurado o respeito à diversidade cultural religiosa do Brasil, vedadas quaisquer formas de proselitismo. $1^{\circ}$ Os sistemas de ensino regulamentarão os procedimentos para a definição dos conteúdos do ensino religioso e estabelecerão as normas para a habilitação e admissão dos professores. $\S 2^{\circ}$ Os sistemas de ensino ouvirão entidade civil, constituída pelas diferentes denominações religiosas, para a definição dos conteúdos do ensino religioso" (BRASIL, Constituição (1988). Decreto-lei $n^{\circ}$ 9475/97, 20 de dezembro de 1996. Lex: legislação federal e marginalia, 1996. Disponível em: <https:// www.jusbrasil.com.br/topicos/11690993/artigo-33-da-lei-n-9394-de-20-de-dezembro-de-1996>. Acesso em: 25 fev. 2018.

5 BRASIL, 1996. 
nos espaços escolares. Mesmo quando dispõem em seu currículo do componente curricular ER, algumas escolas optam por não desenvolver os conteúdos mínimos dessa disciplina deixando de problematizar e dar o tratamento adequado ao problema da (in)tolerância religiosa.

Por outro lado, dados observados em nossa pesquisa de mestrado intitulada "O PIBID de Ensino Religioso como política pública de combate à intolerância religiosa" (2017) mostram certa fragilidade em se garantir tratamento igual às tradições religiosas em contexto de diversidade nos espaços escolares, uma vez que a religião possui sua carga de subjetividade e que há certa debilidade na formação docente para o ER. Essa observação sugere que os próprios docentes, ao manipularem essa disciplina, que requer certo distanciamento do seu próprio credo para que sua abordagem seja de fato dialógica e reflexiva, muitas vezes se veem desafiados em sua prática pedagógica e nem sempre conseguem fazê-lo com a criticidade necessária.

\section{Tolerância versus (in)tolerância ou intolerância?}

Fazem-se necessárias, neste momento, algumas inferências de ordem semântica para que o/a leitor/a seja situado na problemática quanto ao significado atribuído a certos termos ao longo das recentes configurações histórico-sociais, que em certa medida complicam o entendimento acerca dos termos que se seguem. Na verdade, não se trata de polarizar os termos TOLERÂNCIA versus (IN)TOLERÂNCIA, mas compreender que a tolerância que se espera ser benéfica pode ser uma forma de (in)tolerância disfarçada estrategicamente para evitar conflitos. Em situações cotidianas, a intolerância vem sendo praticada por meio de uma pseudotolerância, que se revela, por exemplo, em brincadeiras que hierarquizam as tradições religiosas no Brasil.

Trata-se, então, de despir o termo (in)tolerância de sua carapaça de "politicamente correto", discernindo assim o genuíno do "pseudo". E assim, dessa linha em diante será utilizada a forma INTOLERÂNCIA (sem parênteses no prefixo de negação) por identificar que a forma grafada (IN)TOLERÂNCIA (com o prefixo de negação entre parênteses) fragmenta seu sentido, confundindo-o.

Propõe-se, assim, uma tentativa de entender a diferença nos termos do Outro, pressupondo conhecer suas cosmologias em escalas equivalentes, enquanto sujeito-sujeito e não como sujeito-objeto. Tolerar não significa ser indiferente aos discursos e expressões religiosas nem conceder espaços para que o Outro se manifeste, porque estaríamos novamente reproduzindo o erro da hierarquização. Neste artigo, compreendemos que tolerar pressupõe negociação e reconhecimento da legitimidade do Outro em sua totalidade. Desta forma, assumimos que tolerância pressupõe a totalidade das diferenças e as reconhece em sua legitimidade.

$\mathrm{O}$ termo tolerância, mesmo não sendo o mais adequado para exprimir toda a complexidade que envolve o tema, ainda se configura como uma chave de conhecimento das civilizações modernas. Isso nos ajuda a refletir sobre a rejeição a um tipo de fenômeno religioso que, de acordo com a sua procedência, vai determinar maior ou menor grau de aceitação. 
Quando certo sujeito se abstém (tolera) frente ao que ele reprova, ele está sumariamente se privando e privando o Outro de se relacionarem e se reconhecerem. Isso se configura em uma forma velada de preconceito, como um dispositivo de invisibilização da alteridade. Uma prática bastante recorrente no que concerne a certos tipos de tratamento concedidos à população negra em nosso país. O preconceito racial existe no Brasil, porém está escamoteado pelo mito da democracia racial, que nos faz acreditar que vivemos harmonicamente numa feliz miscigenação. ${ }^{6} \mathrm{O}$ preconceito, assim como a falsa tolerância, estaria implícito nos olhares, nos gestos e nos discursos sobre a alteridade negra. ${ }^{7}$

\section{O PIBID de Ensino Religioso}

Pensando em como muitos alunos e alunas estão sofrendo discriminações das mais variadas maneiras, as quais comprometem o desenvolvimento de sua própria trajetória escolar, é que utilizamos da experiência do Programa Institucional de Bolsas de Iniciação à Docência (PIBID) de ER para destacar alguns dispositivos da intolerância religiosa numa escola da rede estadual de ensino de Juiz de Fora, onde o componente Ensino Religioso está previsto em seu currículo. A despeito desse programa ter primeiramente objetivo de formação e qualificação de licenciandos para o magistério qualificado na rede pública de ensino, neste caso, tomamos o PIBID como evidência de uma prática de ensino preocupada em desconstruir e ressignificar as conotações negativas atribuídas a certas tradições religiosas que acabam por excluí-las do cotidiano escolar.

Tendo em vista que o PIBID é classificado como política pública, por isso sujeito às intempéries governamentais e, portanto, às precariedades estabelecidas por jogos de interesse e disputas políticas cada vez maiores, desde que teve início em 2014, esse programa tem sido submetido à prova cotidianamente, precisando reafirmar seus objetivos, relevância e contribuição para o processo formativo de professores a cada ano. Para tanto, tem lançado mão de espécie de militância em seu favor, protagonizada pelos licenciados-bolsistas, supervisores, coordenadores de subprojetos, coordenadores institucionais e outros envolvidos, que visa garantir a manutenção do projeto até sua conclusão em $2018 .^{8}$

6 SCHWARCZ, Lilia Katri Moritz. O espetáculo das raças. São Paulo: Cia. Das letras, 1995. p. 231.

7 Para uma discussão sobre a naturalização do preconceito étnico no Brasil e os efeitos da invisibilização da alteridade negra, ver SCHWARCZ, 1995 e SCHWARCZ, Lilia Katri Moritz. Complexo de Zé Carioca. Notas sobre uma identidade mestiça e malandra. Ensaio apresentado na ANPOCS, 1994.

8 Em 11 de abril de 2016 foi publicada a portaria $46^{\circ}$ durante a gestão do então ministro Aloízio Mercadante, que previa a reformulação do PIBID, além de cortes que representaram a diminuição de $50 \%$ a $90 \%$ das bolsas de subsídios a licenciandos, supervisores e coordenadores. Tal medida concretizou o encerramento de cerca de 90 mil bolsas no território nacional. A portaria 46 motivou os envolvidos com o PIBID a se mobilizarem em todo o país por meio de greves nas IES federais e estaduais em prol da manutenção do programa, sob ameaça de encerramento em 2017 e manutenção do número de bolsas. Dentre as demais demandas que foram apresentadas pelos coordenadores institucionais do PIBID, a manutenção do programa conforme previa o edital de 2013 foi alcançada. Entretanto, os cortes de bolsas não puderam ser 


\section{Religião e educação}

No interior do PIBID de Ensino Religioso, partimos do suposto que a formação identitária da criança passa pela experiência vivida nos anos de escola, uma vez que nela se desenvolvem aspectos físicos, psicológicos, morais e cognitivos por meio das relações sociais (PIAGET ${ }^{9}, 1975$; VYGOTSKY ${ }^{10}$, 1992; WALLON ${ }^{11}$, 1992). Em se tratando de religião e/ou religiosidade presentes na escola, podemos identificar cenas diversas que vão desde a curiosidade e o questionamento sobre as tradições religiosas e seus costumes, até reações de repugnância e desprezo, muitas vezes, respaldadas em simples falta de conhecimento acerca do que sejam as religiões.

Diante desse quadro de reações variadas, interessou-nos justamente o entendimento sobre a contribuição que o PIBID/ER tem proporcionado na escola onde está em curso, justamente porque sua proposta compreende que há diversidade cultural e sociopolítica nos espaços escolares que exerce influência na forma como se configuram as relações entre educandos, educadores e comunidade escolar em geral. Em princípio, interessou-nos saber como esses atores concebem a diversidade religiosa dentro do ambiente escolar e em que medida o PIBID atenderia a essa demanda de ensino e reflexão sobre a religião, segundo a perspectiva adotada que pretende abordar as tradições religiosas na condição de fenômeno histórico-cultural.

Vale, portanto, compreender que a questão problematizadora que orientou tanto teórica como empiricamente o trabalho do PIBID em Juiz de Fora foi a observação de que existem meninos e meninas em idade escolar que não se veem representados no cenário educacional por inúmeros motivos, dentre os quais está o de ordem religiosa. Além dos estudantes não religiosos, há ainda aqueles estudantes cujo credo não está voltado para as tradições majoritárias, o que resultaria em discriminação de certas tradições ou ausência de tratamento igual no que diz respeito ao conhecimento dessas confissões, suas cosmologias, teologias e sistemas de crenças e práticas religiosas.

Diferente da prática do PIBID, o tratamento universalizante legado ao ER que privilegia as religiões majoritárias em detrimento das não cristãs, como as afro-brasileiras, impõe certa dinâmica de abordagem do religioso no interior da escola que conduz a comunidade discente ao desinteresse pelas aulas que, por sua vez, não seriam significativas. Vale ressaltar que, supõe-se, que elas não sejam significativas justamente por não contemplarem as diversidades presentes na escola. Daí certa vulnerabilidade do processo de ensino-aprendizagem, desconectado da realidade concreta dos educandos e das educandas que, desde então, compromete-o até o ponto de ocasionar o fracasso ou evasão escolar. A não abordagem do conhecimento de tradições afro-brasileiras no contexto escolar contribuiu para a afirmação de entendimentos equivo-

completamente evitados, o que ocasionou significativa precarização do programa em seus dois últimos anos de atuação em diversas universidades ao longo do território nacional.

9 LA TAILlE, Yves de; OLIVEIRA, Marta Kohl de; DANTAS, Heloysa. Piaget, Vygotsky, Wallon: teorias psicogenéticas em discussão. São Paulo: Summus, 1992. p. 66.

${ }^{10}$ LA TAILLE; OLIVEIRA; DANTAS,1992, p. 75.

${ }^{11}$ LA TAILLE; OLIVEIRA; DANTAS, 1992, p. 85. 
cados sobre essas religiões, que calcificados justificam a exclusão e a discriminação de meninos e meninas que praticam tais religiões. O impacto de tal lacuna pode ser observado nas relações sociais desses alunos/alunas que uma vez excluído/as de tais discussões e sem se verem representados com legitimidade na escola, passo a passo, começam a internalizar a exclusão como coisa natural, seja na vida social, profissional, econômica etc.

Provas da discriminação, do desrespeito e da ignorância quanto às religiões afro-brasileiras que resultam em entendimentos equivocados e que justificam a exclusão e o preconceito puderam ser identificadas em expressões usadas por discentes, ainda no ciclo fundamental $1\left(1^{\circ}\right.$ ao $5^{\circ}$ ano). Entre elas "macumba" como coisa ruim, maldição e/ou prática de algum malefício, e "macumbeiro" como aquele ou aquela que pratica a macumba com a finalidade de prejudicar alguém ou algum grupo. Entre as crianças somente a citação desse nome gerava constrangimentos e reações de medo. O desconforto, entretanto, não evitava entre as crianças mais velhas a elaboração de piadas e brincadeiras jocosas com respeito às crenças afro-brasileiras, como o candomblé.

No âmbito do PIBID de Ensino Religioso, ocasiões em que expressões como as mencionadas acima emergiram nas discussões sobre religião em sala de aula foram tomadas como situações problema, a partir das quais a reflexão sobre o tema foi sugerida para os/as discentes. $\mathrm{O}$ tratamento de tais questões suscitou não apenas esclarecimentos sobre os significados dos termos, mas também a curiosidade pelas religiões afro-brasileiras, suas narrativas religiosas e suas práticas.

Daí que o conhecimento produzido com base no delineamento do problema, a aproximação dele, sua descrição e a reflexão a respeito do que significava para a comunidade escolar, resultou num tipo de compreensão quanto à religião do outro, em sua totalidade, que entendemos ser fundamental para a erradicação da intolerância religiosa nos espaços escolares. E tal aproximação deu-se em perspectiva fenomenológica, que, nesta pesquisa, propomos ser uma postura de abordagem do religioso em construção que o toma a partir de suas evidências concretas, para então tentar tecer discursos ilustrados sobre ele. Discursos que coloquem sob holofotes os seus significados, do ponto de vista histórico-social até os sentidos construídos pelos sujeitos religiosos a partir de suas vivências da religião.

\section{A perspectiva compreensiva como postura metodológica}

Para analisar as origens e os desdobramentos da intolerância que se processam no interior das construções sociais e históricas, utilizamos principalmente dois autores que, embora estejam distantes temporalmente, possuem pontos de intersecção no que concerne à discussão religiosa, para além da superficialidade do método positivista.

Pode-se dizer que ambos revelam olhares aproximados no que diz respeito à relevância da religião para as sociedades contemporâneas e, principalmente, quanto à centralidade que os discursos religiosos detêm na construção de sentidos que orientam 
condutas sociais e subjetividades. Embora quase um século separe Weber ${ }^{12}$ (1864) e $\operatorname{Asad}^{13}$ (1932), os dois autores analisam a religião através do mesmo recorte sócio-histórico da realidade: a modernidade ocidental.

Weber (1982), por oferecer significativas contribuições acerca das rejeições religiosas do mundo e suas direções, permitiu-nos entender certos aspectos da intolerância religiosa sem perder de vista a necessidade da negociação entre as partes conflitantes. Asad (2010), por sua vez, incentiva-nos a relativizar os conceitos de religião, modernidade e nacionalismo, interpelando-nos a criticar esses termos utilizados no Ocidente ${ }^{14}$, que resultam em processos de exclusão e, portanto, impedem-nos de entender as novas configurações que se estabelecem ao redor do mundo a partir dos movimentos migratórios e de transnacionalização, os quais também têm tido repercussão no Brasil. ${ }^{15}$

O olhar compreensivo para os termos, conforme a perspectiva dos autores supracitados, nos conduziu a uma postura metodológica diante dos conceitos que os toma como ponto de partida para dar início à discussão que circunda o par religião-educação. Modernidade, secularismo, Estado, tradição, tolerância e intolerância, dentre outros termos, constituem chaves para se pensar a relação entre o tratamento do fenômeno religioso em ambiente escolar, se devido ou não, se fazê-lo ou não e, em se reconhecendo a sua legitimidade, como fazê-lo?

Nesse sentido, observou-se que a proposta do PIBID/ER procurou abordar a religião na qualidade de um dos elementos estruturantes na construção do processo cognitivo dos/as alunos/alunas, não porque a totalidade dos discentes seja constituída de religiosos (porque não o é), tampouco porque a religião seja fonte de valores éticos e morais indispensáveis; mas, justamente, por causa do entendimento quanto à centralidade do fenômeno religioso na formação dos Estados modernos, suas sociedades, culturas e tradições. Em outras palavras, parte dos sentidos forjados no Ocidente em relação ao entendimento moderno sobre sociedade, indivíduo e relações sociais expressa também a contribuição de diferentes tradições religiosas que tiveram participação na escrita da história recente. Visibilizá-las e lançar luz sobre o conhecimento delas representa uma ação pedagógica significativa para a construção de relações de equidade em contextos de diversidade religiosa, como se pode observar na sequência.

12 WEBER, Max. Ensaios de Sociologia. 5. ed. São Paulo: Guanabara Koogan, 1982. p. 226.

13 ASAD, Talal. A construção da religião como uma categoria antropológica. Cadernos de Campo, São Paulo, n. 19, p. 263-284, 2010.

${ }^{14}$ MARCOLINI, Adriana; ANDRADE, José H. Fischel de. A política brasileira de proteção e de reassentamento de refugiados - breves comentários sobre suas principais características. Revista Brasileira de Política Internacional, Brasília, v. 45, n. 1, jan.jun. 2002a. p. 173.

${ }^{15}$ A esse respeito, veja: MARCOLINI; ANDRADE, 2002a; MARCOLINI, Adriana; ANDRADE, José H. Fischel de. "Brazil's Refugee Act: model refugee Law for Latin America?" In: Forced Migration Review, Refugee Studies Centre, University of Oxford, n. 12, January 2002b. Disponível em: < http://www.fmreview.org/en/FMRpdfs/FMR12/fmr12full.pdfs. 
Atividades em sala: experimentos de práticas em construção

A unidade escolar que recebeu o PIBID desde o início do projeto em 2014 é chamada Escola Estadual Professor José Freire e está situada na zona norte, região urbana do município de Juiz de Fora. Atendendo a quase 900 alunos distribuídos entre os três turnos, oferece desde o ensino fundamental e médio até a educação de jovens e adultos (EJA). Desses 900 alunos, 25\% são atendidos pelo PIBID. Essa fração representa os anos iniciais da escola atendidos por sete bolsistas, na ocasião em que essa pesquisa foi realizada (entre os anos 2016-2017).

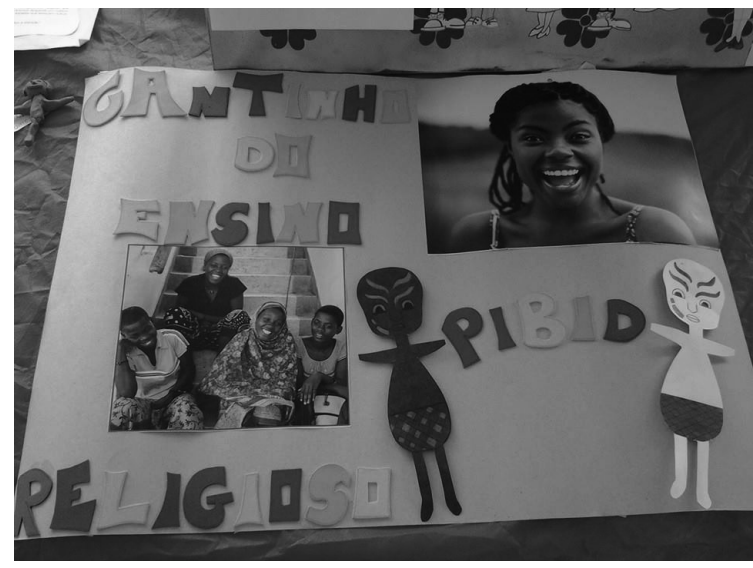

Imagem 1 - Cartaz confeccionado pelos alunos Fonte: Banco de dados do PIBID

Abaixo, seguem algumas abordagens das tradições religiosas realizadas pelo PIBID entre as turmas de $1^{\circ}$ ao $5^{\circ}$ ano do ensino fundamental.

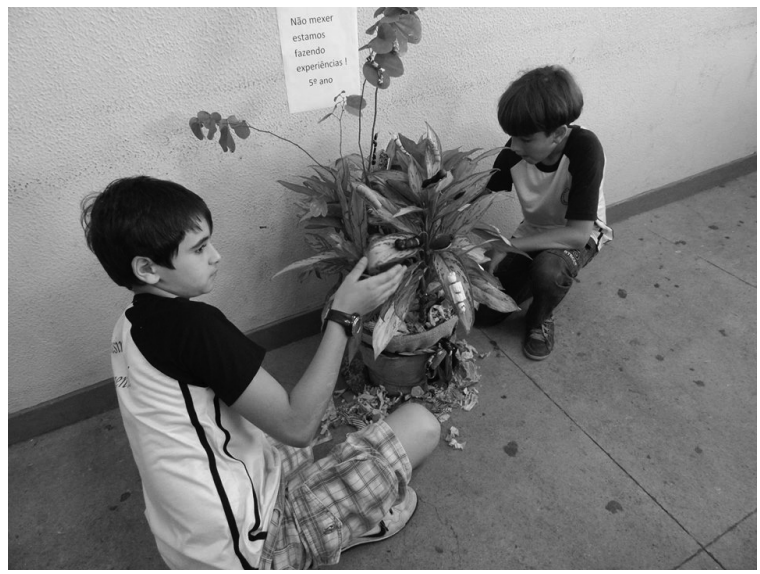

Imagem 2 - Tradições cristãs

Fonte: Banco de dados do PIBID 
O objetivo dessa atividade foi tematizar o significado da Semana Santa para cristãos, especialmente, católicos.

Nesse projeto, as crianças puderam construir sua própria noção a respeito dessa data do calendário católico a partir de uma atividade que teve início com a observação das fases do desenvolvimento de uma borboleta. Os casulos confeccionados pelos licenciandos e deixados numa planta que ornamentava a sala gradualmente transformaram-se e deram lugar a lindas borboletas coloridas, igualmente preparadas pelos bolsistas. Os casulos deram oportunidade para a discussão da noção de reclusão para reflexão, ao passo que as borboletas permitiram a associação com o significado de novo nascimento. Tendo em vista as datas da Quaresma e da Páscoa, essa dinâmica objetivou de modo lúdico permitir às crianças não católicas conhecerem o significado da Quaresma e Páscoa cristãs, segundo o qual trata-se de um período de introspecção e reflexão em que muitos cristãos, especialmente os católicos, se recolhem em oração e jejum visando aproximar-se do sofrimento de Cristo.

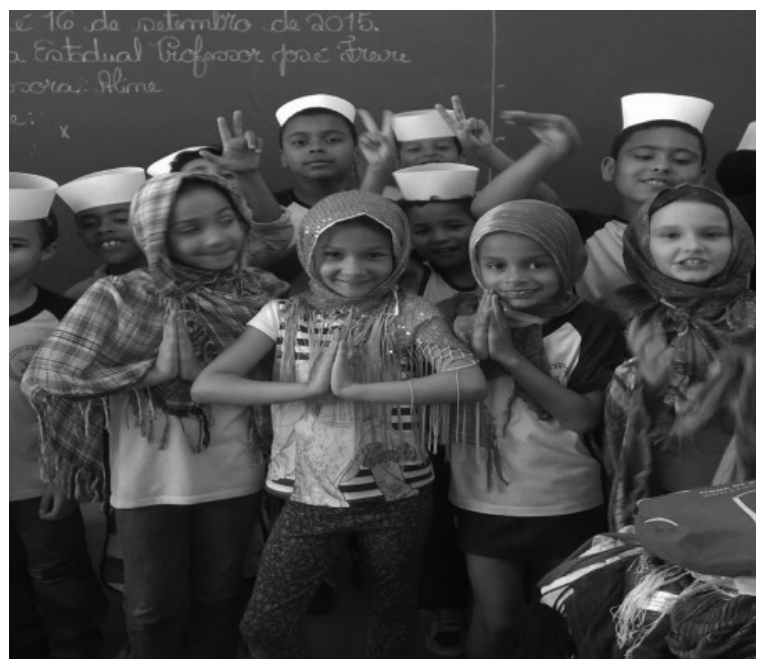

Imagem 3 - Tradição islâmica

Fonte: Banco de dados do PIBID

Essa aula teve como objetivo mostrar alguns elementos do islã. A licencianda do PIBID confeccionou, junto com a turma, os taquiahs, que são usados pelos homens muçulmanos sobre a cabeça. Ela também levou alguns véus islâmicos (hijab) para que as crianças pudessem observá-los e tocá-los, caso quisessem. Dentre as questões que a dinâmica suscitou entre os/as discentes, nessa aula emergiram questionamentos sobre como as mulheres islâmicas conseguem "arranjar" namorados, uma vez que seus rostos e corpos ficariam cobertos. Como mencionado, no âmbito do PIBID tais questionamentos configuram-se em oportunidades para abordar o religioso e, neste caso, elementos religiosos e culturais do islã, que se apresentam estranhos ao modo brasileiro. 

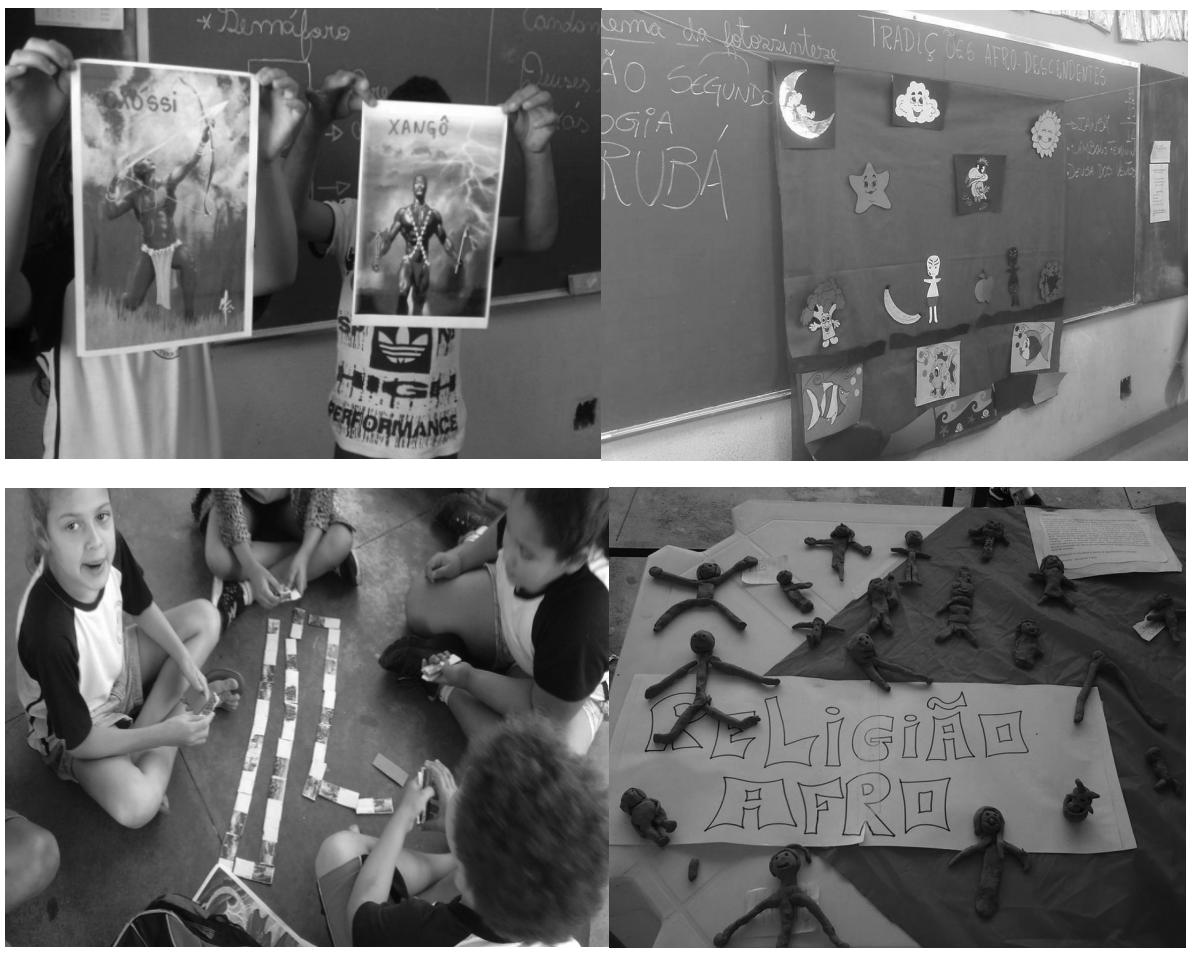

Imagem 4 - Tradições afro-brasileiras

Fonte: Banco de dados do PIBID

Algumas abordagens implementadas no PIBID/ER para explorar as tradições de matriz africana foram iniciadas pela mitologia iorubá, que com base em sua narrativa da criação explica como o mundo surgiu e como o ser humano foi criado. Em uma dessas narrativas, o ser humano veio do barro. Assim, algumas turmas receberam argila para modelar bonequinhos representando esse mito da criação, que inspirou de forma significativa as teologias africanas, enquanto em outra turma foi montado um painel com os elementos da criação. As turmas ainda confeccionaram coletivamente jogos como um "dominó dos orixás", que ligava cada entidade à sua narrativa e principais símbolos. 

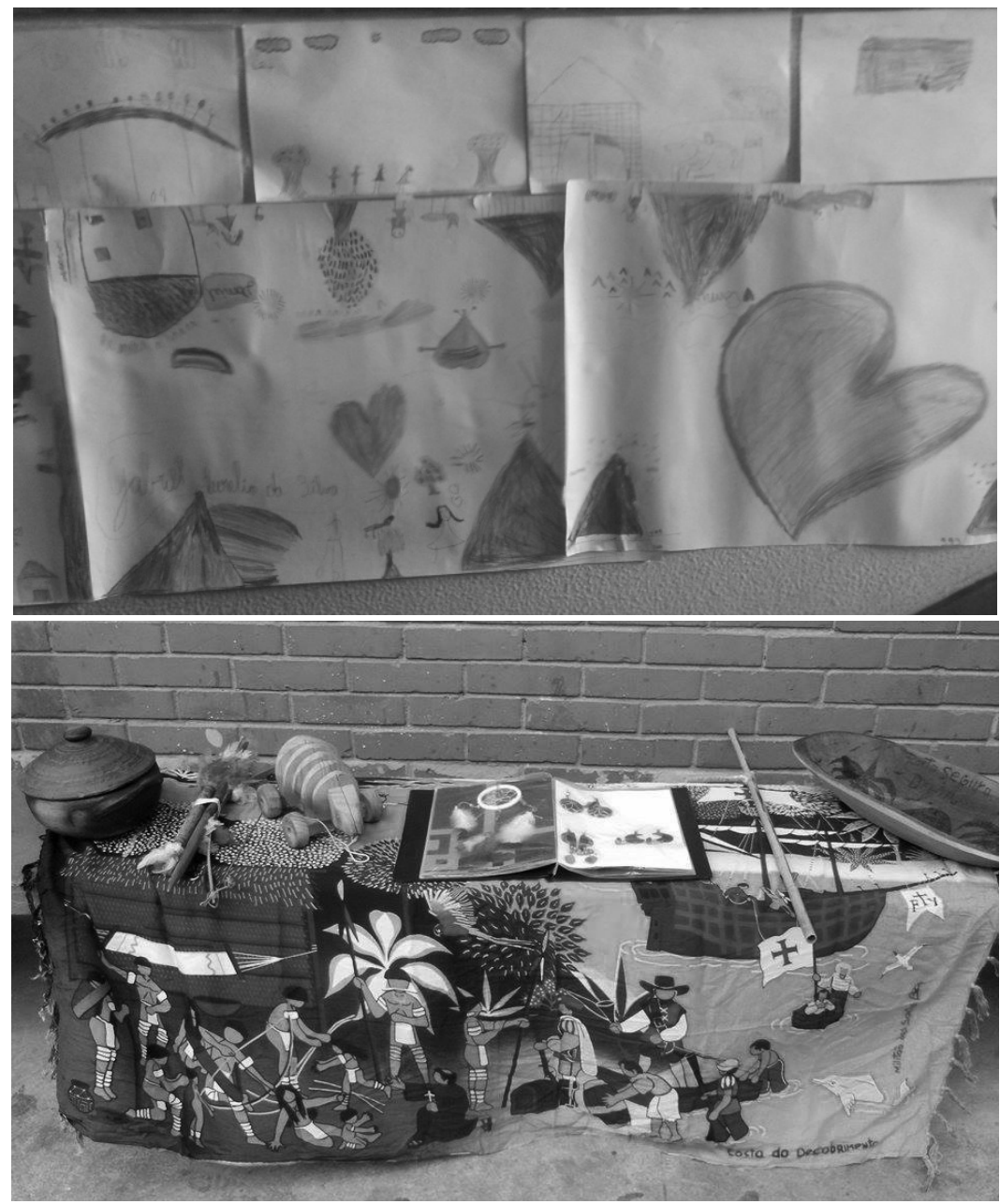

Imagem 5 - Tradição indígena

Fonte: Banco de dados do PIBID

A partir de uma demanda concreta em que se verificou certa desunião numa determinada turma, além de dificuldade em desenvolver trabalhos em grupo, a licencianda usou esse critério para escolher uma tribo indígena chamada ENAWENÊ-NAWÊ, presente no Mato Grosso e que é reconhecida pelo forte senso de comunidade. A partir daí foram explorados vários elementos importantes da tradição dessa tribo que consideravam a cosmologia e a tradição cultural desse povo. 


\section{Considerações finais}

Parte das aulas oferecidas pelo projeto PIBID/ER teve como objetivo trazer à tona a discussão sobre o imaginário coletivo e as estigmatizações que foram feitas em torno de algumas religiões desfavorecidas social e historicamente. Esse processo supõe que o/a educador/a disponha de um olhar cuidadoso subsidiado por instrumental teórico-metodológico que evite a manutenção de práticas obscurantistas. Espera-se que o resultado desse conjunto de práticas conduza a certo tipo de olhar mais respeitoso para o credo e a religião do Outro, pois se entende que conhecer para respeitar faz-se importante ferramenta para evitar que alunos continuem forjando suas identidades de forma hierarquizada em razão de seu credo ou a ausência dele.

Importa salientar que essas aulas mobilizaram diferentes referências teóricas e metodológicas dos estudos de religião para tematizá-la no espaço laico escolar. O ER, por ser uma disciplina situada entre a necessária abordagem da religião enquanto fenômeno histórico-cultural e a mal interpretada laicidade do Estado, encontra entraves pelas próprias tensões que o choque dessas correntes delineia no campo. Assim, a disciplina ER revela, ao mesmo tempo, sua fragilidade e seu poder de conduzir a reflexões mais compreensivas da realidade.

Tais reflexões que envolvem desde aspectos pedagógicos até a delicada questão das subjetividades que cada um enquanto indivíduo possui, seja professor ou aluno, nos desafia a pensar os elementos balizadores de uma transposição didática dos conhecimentos produzidos no espaço acadêmico. Esses balizadores, por sua vez, remetem-nos ao valor que esse conhecimento agrega e em que medida ele faz sentido para a formação plena dos sujeitos, acionando certo tipo de concepção de currículo que cabe a cada gestor escolar discutir com seu corpo de professores.

O PIBID/ER extrapola as dimensões do conhecido estágio curricular porque ele aproxima escola e universidade, pois é pautado numa relação dialética em que a academia, ao mesmo tempo em que se serve da matéria-prima inerente ao campo (escola), oferece respostas para muitos descompassos encontrados na prática pedagógica. Assim contribui para reinventar, reelaborar e repensar novas posturas, num processo baseado em AÇ̃̃̃-REFLEXÃO-AÇÃO.

Nessa perspectiva, o PIBID de Ensino Religioso em Juiz de Fora vem demonstrando o seu papel de agente transformador da realidade, visto que, enquanto política pública de combate à intolerância religiosa, pretende colaborar para a construção de equidade nas relações sociais em contexto de diversidade religiosa.

\section{Referências}

ASAD, Talal. A construção da religião como uma categoria antropológica. Cadernos de Campo, São Paulo, n. 19, p. 263-284, 2010.

BRASIL, Constituição (1988). Decreto-lei no 9475/97, 20 de dezembro de 1996. Lex: legislação federal e marginalia, 1996. Disponível em:<https://www.jusbrasil.com.br/topicos/11690993/ artigo-33-da-lei-n-9394-de-20-de-dezembro-de-1996>. Acesso em: 25 fev. 2018. 
FUNDAÇÃO CAPES. Disponível em: <http://www.capes.gov.br/historia-e-missao>. Acesso em: 02 jan. 2017.

GATTI, Bernadete Angelina; BARRETO, Elba Siqueira de Sá; ANDRÉ, Marli Eliza Dalmazo de Afonso. Políticas docentes no Brasil: um estado da arte. Brasília: UNESCO, 2011.

GRUEN, Wolfgang. Ciências da religião numa sociedade multicultural. Horizonte, Belo Horizonte, v. 3, n. 6, p. 15-26, 2005.

JUNQUEIRA, Sérgio Rogério Azevedo. A relação entre a formação do professor e a identidade do Ensino Religioso. Revista Brasileira de pesquisa sobre formação docente, Belo Horizonte, v. 5, n. 8, p. 121-135, jan./jun. 2013. Disponível em: <http://formacaodocente.autenticaeditora. com.br>. Acesso em: 20 out. 2016.

. Uma ciência como referência: uma conquista para o Ensino Religioso. Rever, Curitiba, n. 2, p. 10-24, jul./dez. 2015.

LA TAILLE, Yves de; OLIVEIRA, Marta Kohl de; DANTAS, Heloysa. Piaget, Vygotsky, Wallon: teorias psicogenéticas em discussão. São Paulo: Summus, 1992.

MARCOLINI, Adriana; ANDRADE, José H. Fischel de. A política brasileira de proteção e de reassentamento de refugiados - breves comentários sobre suas principais características. Revista Brasileira de Política Internacional, Brasília, v. 45, n. 1, jan./jun. 2002a.

"Brazil's Refugee Act: model refugee Law for Latin America?" In: Forced Migration Review, Refugee Studies Centre, University of Oxford, n. 12, January 2002b. Disponível em: $<$ http://www.fmreview.org/en/FMRpdfs/FMR12/fmr12full.pdf $>$.

REVIDE. A outra face do islã. mar. 2015. Disponível em: $<$ http://www.revide.com.br/editorias/ entrevista/outra-face-do-isla/>. Acesso em: 04 jan. 2017.

RODRIGUES, Elisa. Ensino religioso, tolerância e cidadania na escola pública. Numen, Juiz de Fora, v. 16, n. 1, p. 763-782, 2013. Disponível em: <http://numen.ufjf.emnuvens.com.br/numen/ article/view/2126/1935>. Acesso em: 03 abr. 2016.

. O que é isso que chamamos Fenomenologia da Religião? Reflexões em curso. In: SILVEIRA, Emerson; COSTA, Waldney de Souza Rodrigues (Orgs.). A polissemia do sagrado. Os desafios da pesquisa sobre religião no Brasil. São Paulo: Fonte Editorial, 2015. p. 105-119. SCHWARCZ, Lilia Katri Moritz. O espetáculo das raças. São Paulo: Cia das letras, 1995.

. Complexo de Zé Carioca. Notas sobre uma identidade mestiça e malandra. Ensaio apresentado na ANPOCS, 1994.

WEBER, Max. Ensaios de Sociologia. 5. ed. São Paulo: Guanabara Koogan, 1982. 